\title{
Beyond colour-blindness: Enhancing cultural and racial identity for adopted and fostered children in cross-cultural and transracial families
}

Anita Gibbs University of Otago, New Zealand

\begin{abstract}
INTRODUCTION: Cross-cultural and transracial adoption or fostering is a common experience in adoptive and foster family formation yet few adoptive or foster parents are truly competent to address the cultural needs of children who join their families in this way. Few parents comprehend the full extent of cultural and, or, racial identity knowledge that their newly adopted children bring with them. Parents also struggle to answer the cultural, and, or, racial identity questions that their adopted children ask them. Likewise, human service professionals, when helping families, sometimes struggle to provide culturally competent knowledge and training.
\end{abstract}

METHODS: A review of literature nationally and internationally to ascertain best practice models and strategies to help families and professionals move beyond colour-blind approaches and meet the cultural needs of adopted or fostered children.

FINDINGS: There are useful models of cultural and bicultural competency that parents and human service professionals can use to enable improved support for families formed through transracial and cross-cultural adoption and fostering.

CONCLUSIONS: A colour-blind approach to cross-cultural or transracial parenting is unlikely to help children view their ethnic background and heritage positively. Rather, a culturally competent approach will help children develop positive racial and cultural identities.

KEYWORDS: adoption; fostering; cross-cultural; transracial; parenting; human service professionals

Thousands of children are adopted and fostered globally, and most of these would be regarded as transracial and, or, cross-cultural (Compton, 2016). Transracial, cross-cultural, and transcultural are terms often used interchangeably to describe the adoption or fostering of children into families where the culture, race or ethnicity of one or more of the parents is different to that of the child. For the purposes of this article, transracial is used when referring to differences in skin colour, for example, White parents parenting
Black children (Barn \& Kirton, 2012). For cross-cultural, I mean differences in culture, for example, European or Pākehā parents parenting Romanian-born children. In Aotearoa New Zealand, we mostly use this term but sometimes the term transcultural is used (Haenga-Collins \& Gibbs, 2015). All of these examples could also mean differences in ethnicity. Some adoption and fostering arrangements are both transracial and cross-cultural, for example, Pākehā parents fostering Māori children. 
Globally, there are around 16,000 intercountry adoptions, most of which would fit the cross-cultural and transracial profile (Mohanty, 2014). Within-country or domestic adoptions also account for significant transracial and cross-cultural adoption and fostering family arrangements (see Barn \& Kirton, 2012; Evan B. Donaldson Adoption Institute, 2009; Dance, Ouwejan, Beecham, \& Farmer, 2010; Selwyn et al., 2010 for discussions of within-country adoption in the USA and UK). In Aotearoa New Zealand, we have a history of thousands of Māori children being adopted to Pākehā parents in domestic adoption arrangements (Haenga-Collins \& Gibbs, 2015). Between 1955 and 1985, over 45,000 cross-cultural adoptions took place; these adoptions were closed, there were no previous family ties between children and their new parents, and ultimately, many of these adoptions were harmful to the identity and well-being of the Māori adoptees (Haenga-Collins \& Gibbs, 2015). Nowadays, cross-cultural adoptions (domestic adoptions) are rare; however, Aotearoa New Zealand still has cross-cultural fostering. There are no official numbers on cross-cultural fostering but we do know that $50 \%$ of the children in care are Māori, and that many of these children are in foster families that are not Māori (Connolly, De Haan, \& Crawford, 2014). In addition, Aotearoa New Zealand also has approximately 25 transracial and cross-cultural adoptions (internationally) every year where the adopting parents have no previous relationship with the child (Gibbs, 2015). These children come to Pākehā families from countries like China, India, the Philippines, Lithuania, and Thailand. There are also a substantial number of Pacific Island children coming to join relatives in Aotearoa New Zealand but these are not the subject of this current article (Gibbs \& Scherman, 2013).

Transracial and cross-cultural adoptions are controversial and contested, at both international and national levels, with continuing concerns about child trafficking, fear of cultural genocide, what constitutes an orphan, the need for cultural and racial matching of parents to children, and whether it is in the best interests of the child to place

them in families where their racial and cultural needs may not be met (Barn \& Kirton, 2012; Compton, 2016; Hall \& Steinburg, 2013, Morrison, 2004; Tanga \& Nyasha, 2017).

Aotearoa New Zealand follows international conventions on adoption, notably, The Hague Convention (1993) the "Protection of Children and Co-operation in Respect of Intercountry Adoption", and within the country, its policies clearly favour placing children with matched race and matched culture families (Connolly et al., 2014; Oranga Tamariki, 2017). In Aotearoa New Zealand, we have enshrined in legislation the need to ensure that the cultural needs of all children in formal care arrangements are met, particularly through the involvement of kin in both fostering arrangements and in key decision-making processes (Connolly et al., 2014; Gibbs \& Scherman, 2013).

Before looking at the issues for parents and their racially or culturally different children it is important to define culture, cultural competence, colour-blind or culture-blind, and bicultural competence as these terms are used throughout this article. Culture is a multifaceted concept and difficult to define but, for this article, I refer to culture as a system of shared beliefs, values, customs, language and behaviours that are demonstrated by specific groups of people, who may be born into a group or groups but may also choose to belong to a group, or might be adopted and fostered into a group (see also Zion \& Kozleski, 2005). An important consideration in any discussion of culture would be to acknowledge its fluidity, flexibility and contestability. People will always have varying views of what culture is and how they might incorporate what they call culture into their own experiences, and in their relationships with others. Cultural competence can be defined as efforts made by parents and others to expose their children, or clients, to knowledges and practices from their birth culture, as well as to prepare and support them as they encounter racial bias and cultural discrimination in the society in which they live (Lee, Vonk, \& Crolley-Simic, 2015). Again, 
this term is somewhat fluid and has multiple meanings, such that one has to be careful to explain what cultural competence might mean in different contexts. For a Russian child living in Aotearoa New Zealand with European parents, cultural competence might come to mean celebrations of key Russian events, and some use of Russian language and customs. For a Māori child living with kin in a fostering arrangement in Aotearoa New Zealand, the understanding of cultural competence would be different; there would need to be acknowledgement of Māori language, cultural customs, cultural practices and whakapapa (genealogy) being part of everyday life. Colourblind or culture-blind are terms used to describe how people fail (often through ignorance) to acknowledge cultural or racial diversity and difference, and take for granted the privilege of their own race or culture (Zion \& Kozleski, 2005).

Finally, bicultural competence which, in a country like Aotearoa New Zealand, is extremely relevant to any discussion of parenting children, whether adopted or fostered or not. Bicultural competence in the Aotearoa New Zealand context is focused on relationships between Māori and Pākehā and brings together indigenous and non-indigenous practices and knowledge to enhance people's well-being and their sense of identity (Eketone \& Walker, 2015). In a more general context, bicultural competence might refer to being grounded in the relevant cultures, having knowledge of cultural values, and having an ability to communicate these, often through language fluency in both languages (Thomas \& Tessler, 2007). In Aotearoa New Zealand, human service professionals, including social workers, are required to demonstrate bicultural competence and we shall explore how human service professionals can help parents enhance the cultural and racial identity of their fostered or adopted children in the final section of this article.

Adoptive and foster parents themselves are often ill prepared to start their parenting journey when it comes to a nuanced awareness of the cultural and racial identity needs of their children. Research shows that, all too often, adoptive or foster parents see cultural or racial identity as unimportant (Goar, Davis, \& Manago, 2017; Donaldson Institute, 2016). Parents also fear that emphasising difference might lead to problems with the development of a sense of belonging in the new family (Barn \& Kirton, 2012). However, a cultureblind or colour-blind approach to parenting children in cross-cultural or transracial situations might lead to significant distress, and a diminishment of identity and cultural related heritage for the children as time passes (Donaldson Institute, 2016; Haenga-Collins \& Gibbs, 2015; Vonk, 2001). Culture- or colourblindness fails to take account of either racial or cultural diversity and should not be an option in transracial or cross-cultural adoptions and fostering. Thankfully, there are numerous examples of adoptive parents attempting to enhance cultural and racial identity, especially in intercountry adoption, but also in domestic adoptions (Crolley-Simic \& Vonk, 2008; Gibbs, 2015; Goar et al., 2017; Heimsoth \& Laser, 2008; Huh \& Read, 2008; Morrison, 2004; Traver, 2012; Thomas \& Tessler, 2007; Scherman \& Harré, 2004). These studies and other material focused on concepts and models that help families become more culturally competent have direct relevance for adoptive and fostering parenting practice in Aotearoa New Zealand. The motivation for writing this piece is my own personal journey of crosscultural parenting of two children born in Russia. In the rest of this article, I will explore the cultural needs of children; useful models of bicultural and cultural competence; how I have used these models in my own parenting and finally how human service professionals can support adoptive and foster parents to be culturally competent.

\section{Cultural needs and challenges for adopted and fostered children}

Children who are adopted or fostered commonly have traumatised backgrounds and other risk factors that impact on their chances of having stable and positive childhoods (Gibbs, 2015). If they are adopted or fostered 
by relatives or non-relatives the journey towards some certainty in relationships begins. Most newly adoptive parents and long-term foster parents make it a priority to love, commit to, and provide a nurturing and secure environment for their new family members. The basic physical and emotional needs of these children are typically the priority for parents. Alongside these needs will be a range of cultural, racial, spiritual and identity needs that are pivotal to the development of positive identity and survival in a different culture to that of a child's birth. According to Gibbs (2015), these needs and challenges are summarised as follows:

- new language acquisition and possible continued use of birth language;

- coming to terms with their background culture, and, or, race, as well as loss of birth culture and connections;

- understanding and acquiring knowledge of background cultural norms, genealogy, expectations, and practices, including spiritual practices;

- opportunities to participate in cultural activities and beneficial experiences related to country and culture of birth;

- positive development of dual or multiple racial and cultural identities;

- $\quad$ being able to explore difference, diversity and belonging in a safe and open environment;

- developing survival strategies to cope with racism and oppression that they may face in the broader environments of their adoptive or foster families.

There are challenges for adoptive parents and foster parents if they choose a path of "cultural consciousness" whereby they sensitively navigate unfamiliar terrain in their attempts to enhance and support their children's racial and cultural identities (Goar et al., 2017). Barriers include: a lack of proximity to racially and culturally diverse environments, particularly those belonging to their child's birth country; giving undue attention to the different background or heritage of the child and inadvertently making them feel so different that they feel they do not belong or are not wanted; a fear of being perceived of as tokenistic when attempting to learn some of the language or cultural practices of the child; and not wanting to force anything on the child if they are not expressing an explicit interest in learning about their cultural or racial heritage (Crolley-Simic \& Vonk, 2008; Huh \& Reid, 2000; LaFrombosie, Coleman, \& Gerton, 1993; Scherman, 2010; Scherman \& Harré, 2004; Wall, 2012).

Many children in transracial and cross-cultural family situations have had a limited connection to their previous culture (Scherman, 2010), especially if they have resided in orphanages or were removed from their first homes early in life. Hence, foster and adoptive parents will need to make a proactive choice to gain knowledge and understanding about their child's heritage, and be willing to ask for help, for example with language learning, cultural protocols and world views. This requires determination and transparency, and it is easier for most parents to default to ignorance and a colour-blind approach which ultimately leads to cultural assimilation; this is one of the main reasons against transracial or cross-cultural adoption and fostering (Goar et al., 2017; Morrison, 2004). In Aotearoa New Zealand, HaengaCollins and Gibbs (2015) highlighted this for Māori in a study that explored the issues for Māori cross-cultural adoptees who wanted to reconnect and appreciate their birth cultural heritage. A number of adult adoptees in the study felt guilty for creating distance between themselves and their European adoptive parents because they wanted to reconnect to their birth cultures but had been raised only in a Pākehā culture with little or no reference to Māori customs and practices. Māori crosscultural adoptees talked about a deep sense of loss of their birth culture and their sadness at not feeling they belonged to their birth culture when they finally met birth relatives.

It is my contention that adoptive parents and foster or kin caregivers should never deny their adopted children their ethnic, cultural and identity roots, this, in effect, is a 
colour-blind approach, as it neutralises the past and effects cultural assimilation by ignoring difference. I believe parents can promote the cultural and racial well-being of cross-culturally and transracially adopted and fostered children. This allows for parents to both build a sense of sameness and difference, common bonds as well as diversity, a valuing of a child's birth heritage, and a connecting to their new family heritage. We should imagine future alternative family arrangements where parents are firmly committed to the cultural and racial well-being of their children, one in which children are able to feel secure and valued not just in terms of physical or emotional needs being met, but one where children are strong in their sense of who they are and where they came from. We now explore models of bicultural and cultural competency.

\section{An early model of being bicultural}

LaFromboise et al. (1993) outlined a general model of bicultural competency for people from different cultural backgrounds, and developed a set of key bicultural competency factors from extensive searches in the psychological, sociological, educational and ethnology literature. Six key tasks noted by these authors as important to becoming bicultural were:

1] Having knowledge of cultural beliefs and values of everyday practices and rituals of more than one culture, and "an understanding of the basic perspectives a culture has on gender roles, religious practices, and political issues, as well as the rules that govern daily interactions among members of the culture" (LaFromboise et al., 1993, p. 403).

2] Having positive attitudes towards both cultural groups, included being motivated to value the cultures intrinsically, and appreciate the strengths and qualities of dual cultures, as well as avoiding the valuing of one culture above the other.

3] Having bicultural efficacy - LaFromboise et al. (1993, p. 404) noted: "the belief that one can develop and maintain effective interpersonal relationships in two cultures, is directly related to one's ability to develop bicultural competence." This is about building confidence to live comfortably in two cultures, something which, in Aotearoa New Zealand, is desirable, but ultimately challenging for the majority of people who identify as being of European descent or background. Eketone and Walker (2015) offer specific ideas of how bicultural efficacy can be achieved, and I explore these ideas in the section on human service professionals later.

4] Developing communication ability an important component of bicultural competence, especially to be truly bicultural, is a person's ability to effectively communicate to and within a given culture both spoken and non-verbal communication.

5] Having a role repertoire - LaFromboise et al. (1993, p. 406) defined this as "the range of culturally or situationally appropriate behaviors or roles an individual has developed. The greater the range the higher the level of cultural competence." For example, fluent speaking and writing in Te Reo reveals a greater role repertoire than just learning a few songs and greetings.

6] Experiencing groundedness - which is about establishing stable social and support networks in both cultures (LaFromboise et al., 1993).

In reality, it is almost impossible for adoptive and foster parents to be truly bicultural (Scherman, 2010). Unless one of the parents is fluent in both the language and customs of the country or culture of origin, or they themselves were born in the same place as their adopted or fostered child, it is very unlikely that they can enable both cultures to be accorded equal time and commitment. This does not mean that they cannot value two or more cultures, or make concerted efforts to embrace aspects of their children's birth culture. Equally, children who are adopted from orphanages or other forms of state care may not have had much opportunity to be proficient 
in their first language or family of origin cultural knowledge. Adopted children have a tendency to identify with their adopted parents' culture (Scherman, 2010; Scherman \& Harré, 2008). In adoptive family situations, there is a need to balance awareness and positive support of a child's ethnic heritage but also a need to permit a child to feel fully part of an alternative family and its culture (Scherman, 2010). Hence, full bicultural competency might not be quite what adoptive parents or foster caregivers could imagine achieving. Nevertheless, becoming culturally competent is achievable and has been extensively researched by Vonk and colleagues (Vonk, 2001; Crolley-Simic \& Vonk, 2008; Lee et al., 2015). Vonk's model of cultural competency, discussed next, offers a robust model of attitudes, strategies and value positions that may benefit both race conscious parents and professionals in attending to the racial and cultural needs of the placed child.

\section{Being and becoming culturally competent adoptive and foster parents}

Vonk (2001), a USA-based professor and practitioner of social work, has outlined an excellent model of cultural competence that has three core components, that of firstly, racial awareness; secondly, multicultural planning; and thirdly, survival skills. Parents can use these to help their children gain increased racial and cultural competency, and I will give examples of all of these in the following sections.

\section{Racial Awareness}

Firstly, according to Vonk, racial awareness is about understanding one's own racial status, as well as how racism impacts society and individuals. Racial awareness is a vital starting point; if a parent or caregiver has no sense of their own ethnicity or culture then they are less likely to be sensitive to their child's racial or cultural needs. The potential for colour-blindness and minimising racial and cultural difference is likely in these circumstances. Being racially aware includes having a sense of one's own racial or cultural privilege and how that immediately influences the task of being a cross-cultural or transracial parent. Vonk's list of actions that demonstrate racial awareness include: Understanding self, including one's own cultural background and potential racial bias; recognising stereotypes towards other races and cultures; recognising assumptions about the birth culture of one's children; becoming knowledgeable in the cultural heritage of one's fostered or adopted children; and understanding the needs of one's fostered or adopted children in relation to their racial or cultural status (Vonk, 2001, p. 252).

While some of these strategies and attitudes might not be wholly applicable to the Aotearoa New Zealand context, most of them are helpful and realistic. They do require parents and caregivers to be selfaware, and proactive in their learning. They also require support and this is where human service professionals can help at the outset when a transracial or cross-cultural family is being considered. Training and helping soon-to-be parents reflect on why they want to become a parent to a child with a different cultural or racial heritage is a starting point to racial awareness. Often parents focus (rightly so) on the importance of building trusting and secure relationships with their children but this does not negate the need to be racially sensitive.

\section{Multicultural Planning}

Secondly, multicultural planning "refers to the creation of avenues for the transracially adopted child to learn about and participate in his or her culture of birth" (Vonk, 2001, p. 251). This is where parents and caregivers make sustained efforts to expose their children to opportunities for learning about and participating in their cultures of origin, usually at distance for inter-country adoptions but more directly for in-country adoptions or fostering. According to Vonk (2001), examples of multicultural planning 
are: having ongoing contact and activities with people of other races and cultures; ensuring children can attend multicultural schools and live in diverse neighbourhoods; have friends who are good role models of varying cultures for one's children; actively celebrating traditions from one's child's birth culture, including learning the language, and participating actively in ongoing learning about one's child's birth culture; helping all of one's children and their friends benefit from the positives of a fostered or adopted child's birth culture (Vonk, 2001, p. 253).

It may not always be possible to achieve all of these because of the lack of proximity to the child's birth country, or because it is hard to find other people of the same ethnicity within one's locality. But given that research shows exposure to positive role models from one's birth culture can help psychosocial development and achievement of positive cultural identity (Crolley-Simic \& Vonk, 2008; Scherman \& Harré, 2004, 2008; Thomas \& Tessler, 2007), adoptive and foster parents in Aotearoa New Zealand can still achieve many of these. Sometimes it does not need to involve a great deal of effort, even small steps towards promoting a positive understanding and awareness of where the child has come from, as well as enabling them to connect with others with similar cultural and racial backgrounds can go a long way (Thomas \& Tessler, 2007). In New Zealand, we have excellent examples of local support groups for children and young people who have been adopted from Eastern Europe and China in particular. Inter-country Adoption New Zealand (ICANZ), for example, while based in Auckland has an excellent network of regional support groups, where Russian events or similar happen, or where information sharing about trips back to a country of origin occurs (http:/ / www. icanz.gen.nz/). Parents in these kinds of support groups have made great efforts to expose their children to people and cultures that promote positive attitudes towards and knowledge about people and traditions from these parts of the world (Scherman \& Harré, 2004, 2008).

\section{Survival skills}

Thirdly, using survival skills is about: the skills and willingness of parents to prepare their adopted and fostered children to cope successfully with racism (Vonk, 2001). In a cultural competency sense, this is also about helping children cope with negative comments, stereotypes and assumptions about the countries or cultures that they have originated from. In order to help their adopted and fostered children successfully survive the micro and macro racism that they will face, it will be easier if they have made the earlier steps of understanding their own racism or bias, and have valued the different ethnic and cultural backgrounds and identities of their children. They can then help their children to cope with, and challenge, other people's racist comments. They can also challenge organisational and societal barriers that are placed in the way of their children's ethnic wellbeing. Vonk's example of survival skills include: educating one's children about discrimination and racism and how to cope when it occurs in varying contexts; teaching one's children and other children a variety of strategies to recognise and manage discrimination; modelling for them how to do this and how to seek help, especially help that might be beneficial from within the child's birth culture; and ensuring that one's children develop pride in themselves and their birth culture (Vonk, 2001, p. 253).

These suggestions require dedicated time and energy and cannot just be left to parents and their support groups. Human service professionals and other professionals can provide additional resources and ideas either as part of initial training and preparation, and by having a long-term term strategy to help cross-cultural families undertake training, access support, and increase their cultural competency knowledge and skills in the areas noted by Vonk above. 
In a later work, Lee et al. (2015) noted that certain factors were crucial to cultural and racial socialisation practices among international transracial adoptive parents. We have already considered racial awareness being sensitised to one's own race and culture - having this means that parents will be more likely to engage in cultural and racial socialisation practices for their children. This also increases the chances that adoptive and foster parents will have selfefficacy, which means they will be motivated to invest, plan, participate in and provide further opportunities for racial and cultural socialisation. Other factors, like gender, geographical location and income are also important when it comes to likelihood of and effort towards enhancing racial or cultural socialisation. According to Lee et al. (2015, p. 144), mothers place more importance on birth culture and diversity; a higher parental income is also associated with greater cultural and racial socialisation practices, and a good family location, defined as a "diverse neighbourhood and access to the child's birth community through pre-existing friendships", is a great resource to encourage racial or cultural socialisation. Other factors like adoption-related education and support, for example, travelling to the country of origin and participating in adoption support groups after adoption, and the children's actual ethnicity (e.g., some ethnicities/races are more likely to have participation in cultural activities), all influence the amount or type of cultural and racial socialisation practices that parents engage in (Lee et al., 2015; Traver, 2012).

In the next section I illustrate how I have applied a number of the strategies suggested by Vonk and colleagues to my own unique cross-cultural family situation.

\section{A personal note - Cross-cultural parenting}

It is appropriate to offer an illustration of applying the concepts and strategies of cross-cultural parenting as they have influenced my own journey of 10 years with two wonderful adopted boys from
Russia. My husband, daughter and I are of European descent, from Aotearoa New Zealand and England, and our sons and brothers are Russian-born. Our starting point was always that we should value their birth culture and look for ways to help them retain some of what they brought to Aotearoa New Zealand as toddlers but, more importantly, to build a capacity for positive dual cultural identity as they lived in their new country. We did the usual things of learning enough Russian language to get by, of reading books about Russia, of buying Russian toys, chairs, dolls, books, CDs and DVDs. We learnt the alphabet and some songs. We were not able to immerse ourselves in the culture and we were realistic that biculturalism was not possible. However, we have aimed for cultural competence. For our children, as they have grown up, this has meant meeting up with other Russians (when we could find them), meeting regularly with other families who have adopted from overseas, and chatting about Russian festivals, religion, history, culture and politics, in ways that our children could understand and find interesting. All of these things have helped our children feel good about being Russian as well as being Kiwi. The main strategy is openness, no topic is to be avoided and, where we do not have the knowledge, we try and search for it. The most significant thing we have done is help them process and manage racist comments, and microaggressions directed at them as Russians. Overall, they have managed to achieve a positive regard for their birth culture in spite of some discrimination, and negative media attention at times towards their country of birth. There is a lot more we could have done, and hope to do, to ensure our crosscultural children are able to realise their hopes for connecting back and forward to their birth country and culture. Thankfully, we, and other adoptive and foster parents, are not alone in these endeavours, as there are plenty of online resources exploring these issues (see for example, http://www. colorlines.com/articles/white-dad-blackson-and-raising-kids-colorblind-world). 
Finally, I now consider how human service professionals can support adoptive and foster parents to be culturally competent.

\section{Can human service professionals support adoptive and foster parents to be culturally and racially competent?}

Human service professionals often have the opportunity to work alongside families being formed via adoption or fostering, and are in a position to assist parents to meet the cultural and racial needs of their children. The bicultural partnership afforded by Te Tiriti $\mathrm{O}$ Waitangi, as well as implementation of rights-based conventions (for example, The Hague Convention, 1993), strongly promote the rights of adopted and fostered children to keep or foster their language and cultural practices whatever their country of origin, racial or cultural background. An Aotearoa New Zealand model of bicultural practice for human services professionals can be found in the work of Eketone and Walker (2015), who argue that biculturalism recognises two distinct cultures in Aotearoa New Zealand with their own set of values, language and customs. This model would be especially useful for helping families who might be Pākehā but who foster Mãori children. It would assume that human service professionals have a minimum competence in the use of te reo (language), tikanga (customs), kawa (protocols), knowledge of Mãori values and history (Eketone \& Walker, 2015). It would also assume that human service professionals would have competence in European/Pākehā language, customs and so forth. It is important that human service professionals undertake the necessary training (often post-qualification) so that they can work biculturally but also offer training for parents and caregivers in how to support their children on their own culturally diverse journeys.

Human service professionals could apply some of the strategies mentioned earlier, in relation to how they work with families on culture-related matters. Professionals could adapt Vonk and colleagues' model on racial awareness, multicultural planning and survival skills in order to provide help to families with adopted or fostered children. This might allow families to increase their ability to provide positive cultural education to their children, as well as help their children cope with tricky questions that they might be asked about their backgrounds and looks. I recall one incident when some Russian adults visiting our town met my boys and spoke to them in Russian and were puzzled at the boys' lack of language reciprocity, and I could see my boys were not quite sure how to respond but we all had a chat, and the boys explained where they were from and we talked about what Russia was like and the positives of both countries. We are doing well in some respects but, with additional professional and community support, we could go beyond basic survival skills to a more robust acknowledgement and appreciation of the varying cultural dynamics of our culturally diverse family. Having professionals working alongside families can help reinforce positive messages about racial and cultural identity, and convey that appreciating diversity and challenging oppression and racism is a collective, community and family-based endeavour.

\section{Conclusion}

This article has sought to provide guidance for adoptive and foster parents when they are parenting children of a different culture or background to themselves. A colour-blind approach to cross-cultural or transracial parenting is unlikely to help children view their ethnic background and heritage positively. Rather, a culturally competent approach, incorporating a range of attitudes and strategies that demonstrate racial awareness and a commitment to anti-racism or anti-oppression, will help children develop positive racial and cultural identities. Human service professionals can play a key role in helping parents value what 
their foster or adoptive children bring, in terms of their original culture, as well as in helping parents develop positive cultural aspirations for their children in the future.

\section{References}

Barn, R., \& Kirton, D. (2012). Transracial adoption in Britain: Politics, ideology and reality. Adoption \& Fostering, 36(3\&4), 25-37.

Compton, R. J. (2016). Adoption beyond borders. New York, NY: Oxford University Press.

Connolly, M., De Haan, I., \& Crawford, J. (2014). Focus on stability: A cohort of young children in statutory care in Aotearoa New Zealand. International Social Work, 60(1), 111-125.

Crolley-Simic, J., \& Vonk, E. (2008). Racial socialization practices of white mothers of international transracial adoptees. Journal of Ethnic \& Cultural Diversity in Social Work, 17(3), 301-318.

Dance, C., Ouwejan D., Beecham, J., \& Farmer, E. (2010). Linking and matching: A survey of adoption agency practice in England and Wales, London, UK: BAAF.

Donaldson Institute. (2016). Attitudes and perceptions among adoption professionals: Qualitative research report. Retrieved from http://www.adoptioninstitute.org/ publications/attitudes-perceptions-among-adoptionprofessionals-qualitative-research-report/

Eketone, A., \& Walker, S. (2015). Bicultural practice: Beyond mere tokenism. In K. van-Heugten \& A. Gibbs (Eds.), Social work for sociologists: Theory and practice (pp.103-119). New York, NY: Palgrave Macmillan.

Evan B. Donaldson Institute. (2009). Beyond culture camp: Promoting healthy identity formation in adoption. Retrieved from $h$ ttp://www.adoptioninstitute.org/ publications/beyond-culture-camp-promoting-healthyidentity-formation-in-adoption/

Gibbs, A. (2015). Parenting adopted children from other cultures and supporting adoptive parents to meet the needs of adopted children. In N. Roman (Ed.), Parenting: Behaviors, cultural influences and impact on childhood health and wellbeing (pp. 99-122). New York, NY: NOVA.

Gibbs, A., \& Scherman, R. (2013). Pathways to parenting in New Zealand: Issues in law, policy and practice. Kotuitui: New Zealand Journal of Social Sciences Online, 8(1-2), 13-26.

Goar, C., Davis, J., \& Manago, B. (2017). Discursive entwinement: How white transracially adoptive parents navigate race. Sociology of Race and Ethnicity, 3(3), 338-354.

Haenga-Collins, M., \& Gibbs, A. (2015). "Walking between worlds": The experiences of New Zealand Māori crosscultural adoptees. Adoption and Fostering, 39(1), 62-75.

Hall, B., \& Steinburg, G. (2013). Inside transracial adoption. London, UK: Jessica Kingsley.

Heimsoth, D., \& Laser, J. A. (2008). Transracial adoption: Expatriate parents living in China with their adopted Chinese children. International Social Work, 51(5), 651-668.

Huh, N. S., \& Reid, W. J. (2008). Intercountry, transracial adoption and ethnic identity: A Korean example. International Social Work, 43(1), 75-87.
LaFromboise, T., Coleman, H., \& Gerton, J. (1993). Psychological impact of biculturalism: Evidence and theory. Psychological Bulletin, 114(3), 395-412.

Lee, J., Vonk, E., \& Crolley-Simic, J. (2015). A model of factors related to cultural and racial socialization practices among international transracial adoptive parents. Families in Society, 96(2), 141-147.

Mohanty, J. (2014). International adoption: Policy and practice issues. In L. How Kee, J. Martin, \& Ow, R. (Eds.), Cross-cultural social work (pp. 184-194). South Yarra, VIC: Palgrave Macmillan.

Morrison, A. (2004). Transracial adoption: The pros and cons and the parents' perspective. Harvard Blackletter Law Journal, 20(2004), 163-202.

Oranga Tamariki. (2017). Caregiver and assessment approval policy. Retrieved from https://practice.mvcot. govt.nz/policy/caregiver-assessment-and-approval/ index.html

Scherman, R. (2010). A theoretical look at biculturalism in intercountry adoption. Journal of Ethnic and Cultural Diversity in Social Work, 19(2), 127-142.

Scherman, R., \& Harré, N. (2004). Intercountry adoption of Eastern European children in New Zealand: Parents' attitudes toward the importance of culture. Adoption \& Fostering, 28(3), 62-72.

Scherman, R., \& Harré, N. (2008). The ethnic identification of same-race children in intercountry adoption. Adoption Quarterly, 11(1), 45-65.

Selman, P. (2012). The global decline of intercountry adoption: What lies ahead? Social Policy and Society, 11(3), 381-397.

Selwyn, J., Quinton, D., Harris, P., Wijedasa, D., Nawaz, S., \& Wood, M. (2010). Pathways to permanence for black, Asian and mixed ethnicity children. London, UK: BAAF.

Tanga, P., \& Nyasha, K. (2017). Diverse perceptions of cross-racial adoption in South Africa. Research on Social Work Practice, 27(2), 231-238.

The Hague Convention. (1993). Protection of children and co-operation in respect of intercountry adoption. Retrieved from https://www.hcch.net/en/instruments/ conventions/specialised-sections/intercountry-adoption

Thomas, K., \& Tessler, R. (2007). Bicultural socialization among adoptive families: Where there is a will, there is a way. Journal of Family Issues, 28(9), 1189-1219.

Traver, A. (2012). Mothering Chineseness: Celebrating ethnicity with white American mothers of children adopted from China. In F. J. Latchford (Ed.), Adoption and mothering (pp. 103-118). Bradford, ONT: Demeter Press.

Vonk, E. (2001). Cultural competence for transracial adoptive parents. Social Work, 46(3), 246-255.

Wall, S. (2012). Ethics and the socio-political context of international adoption: Speaking from the eye of the storm. Ethics and Social Welfare, 6(4), 318-332.

Zion, S., \& Kozleski, E. (2005). On point: Understanding culture. National Institute for Urban School Improvement. Retrieved from http://guide.swiftschools.org/ resource/185/understanding-culture 